University of Wollongong

Research Online

Faculty of Engineering - Papers (Archive)

Faculty of Engineering and Information

Sciences

2008

\title{
Control of a stand alone variable speed wind turbine with a permanent magnet synchronous generator
}

\author{
M. E. Haque \\ University of Tasmania, mehaque@utas.edu.au \\ Kashem Muttaqi \\ University of Tasmania, kashem@uow.edu.au \\ Michael Negnevitsky \\ University of Tasmania, michael.negnevitsky@utas.edu.au
}

Follow this and additional works at: https://ro.uow.edu.au/engpapers

Part of the Engineering Commons

https://ro.uow.edu.au/engpapers/5406

\section{Recommended Citation}

Haque, M. E.; Muttaqi, Kashem; and Negnevitsky, Michael: Control of a stand alone variable speed wind turbine with a permanent magnet synchronous generator 2008.

https://ro.uow.edu.au/engpapers/5406

Research Online is the open access institutional repository for the University of Wollongong. For further information contact the UOW Library: research-pubs@uow.edu.au 


\title{
Control of a Stand Alone Variable Speed Wind Turbine with a Permanent Magnet Synchronous Generator
}

\author{
M. E. Haque, Member, IEEE, K. M. Muttaqi, Senior Member, IEEE, and M. Negnevitsky, Senior \\ Member, IEEE
}

\begin{abstract}
A novel control strategy for the operation of a permanent magnet synchronous generator (PMSG) based stand alone variable speed wind turbine is presented in this paper,. The direct drive PMSG is connected to the load through a switch mode rectifier and a vector controlled pulse width modulated (PWM) IGBT-inverter. The generator side switch mode rectifier is controlled to achieve maximum power from the wind. The load side PWM inverter is using a relatively complex vector control scheme to control the amplitude and frequency of the inverter output voltage. As there is no grid in a stand-alone system, the output voltage has to be controlled in terms of amplitude and frequency. The stand alone control is featured with output voltage and frequency controller capable of handling variable load. A damp resistor controller is used to dissipate excess power during fault or over-generation. The potential excess of power will be dissipated in the damp resistor with the chopper control and the dc link voltage will be maintained. Extensive simulations have been performed using Matlab/Simpower. Simulation results show that the controllers can extract maximum power and regulate the voltage and frequency under varying load condition. The controller performs very well during dynamic and steady state condition.
\end{abstract}

Index Terms - Permanent magnet synchronous generator, maximum power extraction, switch-mode rectifier, stand alone variable speed wind turbine, voltage and frequency control.

\section{INTRODUCTION}

$\mathrm{V}$ ariable speed wind turbines have many advantages over fixed speed generation such as increased energy capture, operation at maximum power point, improved efficiency and power quality [1]. However, the presence of gearbox that coupling the wind turbine to the generator still causes problems. The gearbox suffers from faults and requires regular maintenance [2]. The reliability of the variable speed wind turbine can be improved significantly by using a direct drive permanent magnet synchronous generator. PMSG has received much attention in wind energy application because of their property of self excitation, which allows an operation at a high power factor and high efficiency [3]. The use of

This work is supported by the Australian research Council (ARC) and Hydro Tasmania Linkage Grant, K0015166.

M.E. Haque is with the School of Engineering, University of Tasmania, Hobart, Australia (e-mail: mehaque@utas.edu.au)

K. M. Muttaqi is with the School of Engineering, University of Tasmania, Hobart, Australia (e-mail: M.Kashem@utas.edu.au)

M. Negnevitsky is with the School of Engineering, University of Tasmania, Hobart, Australia (e-mail: Michael.Negnevitsky@utas.edu.au) permanent magnet in the rotor of the PMSG makes it unnecessary to supply magnetizing current through the stator for constant air-gap flux; the stator current need only to be torque producing. Hence for the same output, the PMSG will operate at a higher power factor because of the absence of the magnetizing current and will be more efficient than the induction machine.

To extract maximum power from the fluctuating wind, variable speed operation of the wind turbine generator is necessary. This requires a sophisticated control strategy for the generator. Optimum power/torque tracking is popular control strategy as it helps to achieve optimum wind energy utilization [4-8]. Some of these control strategies use wind velocity to obtain the desired shaft speed to vary the generator speed. However, anemometer based control strategy increases cost and reduce the reliability of the overall system. These control strategies are not suitable or too expensive for a small scale wind turbine. In [7], the current vector of an interior type PMSG is controlled to optimize the wind turbine operation at various wind speed, which requires six active switches to be controlled. Switch-mode rectifier has been investigated for use with automotive alternator with permanent magnet synchronous machines $[9,10]$. The switchmode rectifier has also been investigated for small scale variable speed wind turbine $[11,12]$.

A control strategy for the generator side converter with output maximization of a PMSG based small scale wind turbine is developed. The generator side switch mode rectifier is controlled to achieve maximum power from the wind. The method requires only one active switching device (IGBT), which is used to control the generator torque to extract maximum power. It is simple and a low cost solution for a small scale wind turbine.

For a stand alone system, the output voltage of the load side converter has to be controlled in terms of amplitude and frequency. Previous publications related to PMSG based variable speed wind turbine are mostly concentrated on grid connected system [6-8]. Much attention has not been paid for a stand alone system. Many countries are affluent in renewable energy resources; however they are located in remote areas where power grid is not available. Local, small scale stand-alone distributed generation system that can utilize these renewable energy resources when grid connection is not feasible. In this paper, a vector control 
system is developed to control the load voltage in terms of the amplitude and frequency in a stand alone mode.

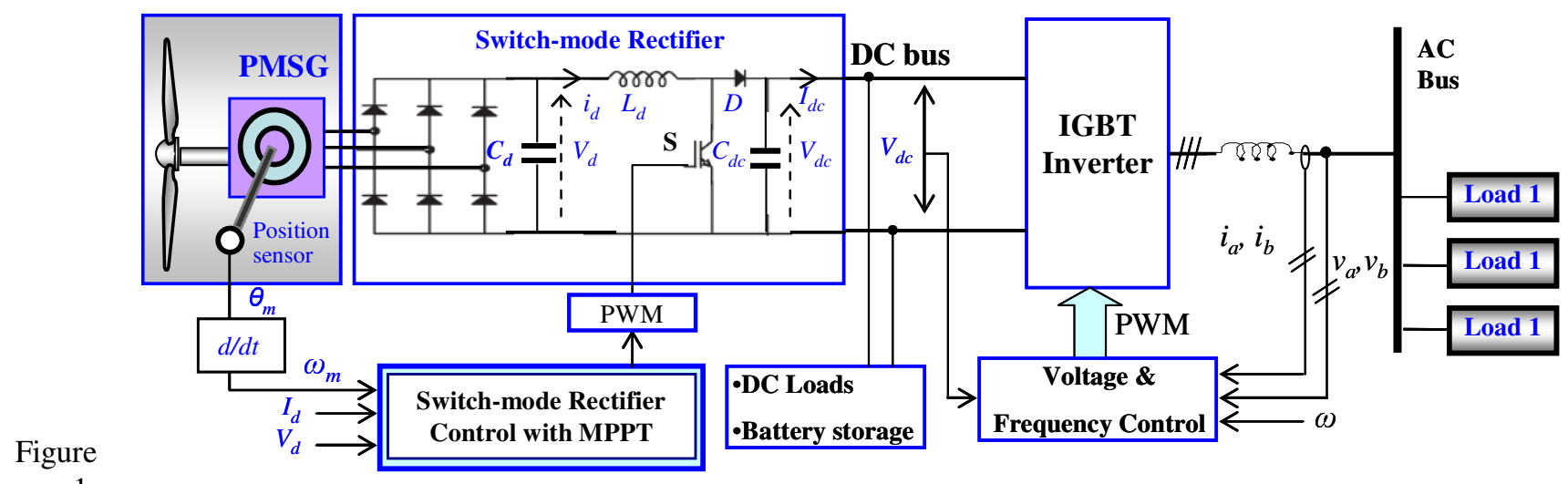

1.

Control Structure of a PMSG based standalone variable speed wind turbine.

\section{System Configuration}

Figure 1 shows the control structure of a PMSG based standalone variable speed wind turbine. The standalone system consists of the following:

- Wind turbine

- Permanent magnet synchronous generator, which is directly driven by the gearless wind turbine.

- A single switch three-phase switch-mode rectifier, which is controlled to extract maximum power from the fluctuating wind.

- A vector controlled PWM voltage source IGBT-inverter to control the amplitude and frequency of the supply voltage.

\section{CONTROL OF GENERATOR SIDE CONVERTER WITH MAXIMUM POWER EXTRACTION}

The output of a variable speed PMSG is not suitable for use as it varies in amplitude and frequency due to fluctuating wind. A constant DC voltage is required for direct use, storage or conversion to $\mathrm{AC}$ via an inverter. In this paper, a single switch three-phase switch-mode rectifier is used to convert the ac output voltage of the generator to a constant dc voltage before conversion to $\mathrm{AC}$ voltage via an inverter.

The single switch three phase switch-mode rectifier consists of a three-phase diode bridge rectifier and a DC to DC converter. The output of the switch-mode rectifier can be controlled by controlling the duty cycle of an active switch (such as IGBT) at any wind speed to extract maximum power from the wind turbine and to supply the loads.

The wind turbine can produce maximum power when the turbine operates at maximum $C_{p}$ (i.e. at $C_{p_{-} o p t}$ ). So it is necessary to keep the rotor speed at a optimum value of the tip speed ratio, $\lambda_{o p t}$. If the wind speed varies, the rotor speed should be adjusted to follow the change.

The target optimum power from a wind turbine can be written as;

$$
\begin{gathered}
P_{m_{-} \text {opt }}=0.5 \rho A C_{p_{-} o p t}\left(\frac{\omega_{m_{-} \text {opt }} R}{\lambda_{\text {opt }}}\right)^{3}=K_{\text {opt }}\left(\omega_{m_{-} o p t}\right)^{3} \\
\text { where, } K_{\text {opt }}=0.5 \rho A C_{p_{-} \text {opt }}\left(\frac{R}{\lambda_{\text {opt }}}\right)^{3}
\end{gathered}
$$

and $\omega_{m_{-} o p t}=\frac{\lambda_{o p t}}{R} v_{w}=K_{w} v_{w}$

Therefore, the target optimum torque can be given by

$$
T_{m_{-} o p t}=K_{o p t}\left(\omega_{m_{-} o p t}\right)^{2}
$$

The mechanical rotor power generated by turbine as a function of the rotor speed for different wind speed is shown in figure 3. The optimum power is also shown in this figure. The optimum power curve $\left(P_{\text {opt }}\right)$ shows how maximum energy can be captured from the fluctuating wind. The function of the controller is to keep the operating of the turbine on this curve, as the wind velocity varies. It is observed from this figure that there is always a matching rotor speed which produces maximum power for any wind speed. If the controller can properly follow the optimum curve, the wind turbine will produce maximum power at any speed within the allowable range. The optimum torque can be calculated from the optimum power given by equation (4). For the generator speed below the rated maximum speed, the generator follows the equation (4).

The structure of the proposed control strategy of the switch mode rectifier is shown in figure 3 . The control objective is to control the duty cycle of the switch $\mathrm{S}$ in figure 1 , to extract maximum power from the variable speed wind turbine and transfer the power to the load. The control algorithm includes the following steps:

- Measure generator speed, $\omega_{g}$.

- Determine the reference torque (figure 4) using the following equation: 


$$
T_{g}^{*}=K_{\text {opt }}\left(\omega_{g}\right)^{2}
$$

- This torque reference is then used to calculate the DC current reference by measuring the rectifier output voltage, $V_{d}$ as given by:

$I_{d}^{*}=\left(T_{g}^{*} \times \omega_{g}\right) / V_{d}$

- The error between the reference dc current (and measured dc current is used to vary the duty cycle of the switch to regulate the output of the switch-mode rectifier and the generator torque through a PI controller.

The generator torque is controlled in the optimum torque curve in figure 4 according to generator speed. The acceleration or deceleration of the generator is determined by the difference of the turbine torque $T_{m}$ and generator torque $T_{g}$. If the generator speed is less than the optimal speed, the turbine torque is larger than the generator torque and the generator will be accelerated. The generator will be decelerated if the generator speed is higher than the optimal speed. Therefore, the turbine torque and generator torque settle down to the optimum torque point $T_{m_{-} \text {opt }}$ at any wind speed and the wind turbine is operated at the maximum power point. For example (considering figure 2), if the PMSG operating at point 'a' and wind speed increases from $v_{w 1}$ to $v_{w 2}$ (point $b$ ), the additional power and hence torque causes the PMSG to accelerate. The accelerating torque is the difference between the turbine mechanical torque and the torque given by the optimum curve. Finally, the generator will reach the point ' $\mathbf{c}$ ' where the accelerating torque is zero. A similar situation occurs when the wind velocity decreases.

In the proposed method, the wind speed is not required to be monitored and therefore, it is a simple output maximization control method without wind speed sensor (anemometer).

\section{VOLTAGE AND FREQUENCY CONTROL OF THE LOAD SIDE CONVERTER}

The objective of the supply side converter is to regulate the voltage and frequency. As there is no grid exists in a standalone system, the output voltages have to be controlled in terms of amplitude and frequency. The control structure for stand-alone control mode is consists of output voltage controller, dc link voltage controller, damping resistance controller and current controller. The Output voltage controller is used to control the output voltage during load transients or wind variation. DC-link voltage controller is used to stabilize the dc link voltage. The dc-voltage PI controller maintains the dc voltage to the reference value. PI controllers are used to regulate the output voltage and currents in the inner control loops and the dc voltage controller in the outer loop. To compensate the cross-coupling effect due to the output filter in the rotating reference frame, compensation terms are added as shown in figure 5. Damp resistor controller is used to dissipate excess power during fault or overgeneration. The potential excess of power will be dissipated in the damp resistor with the chopper control and the de link voltage will

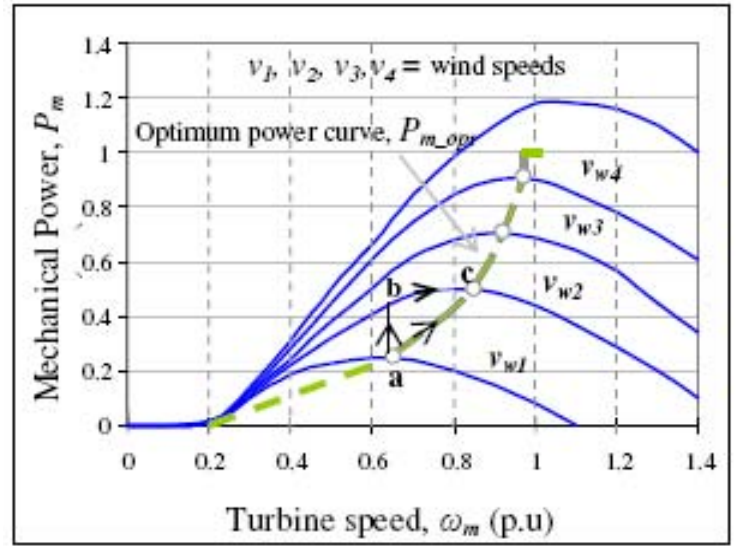

Figure 2. Mechanical power generated by turbine as a function of the rotor speed for different wind speed.

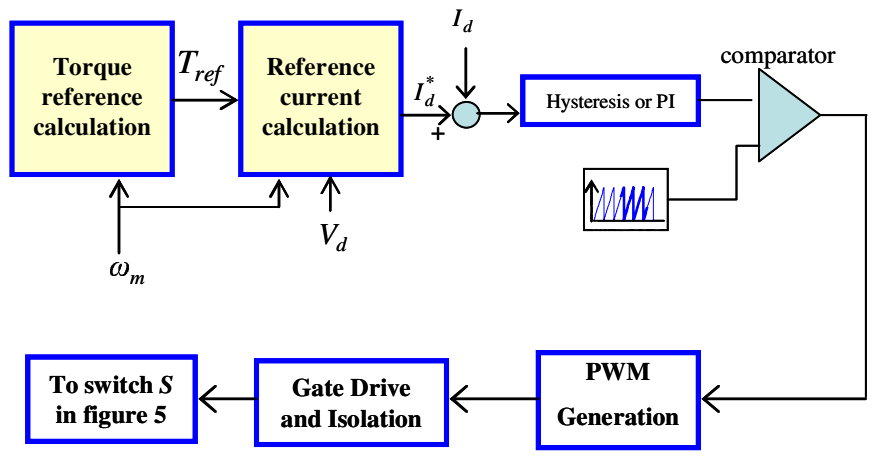

Figure 3. Control strategy of the switch-mode rectifier.

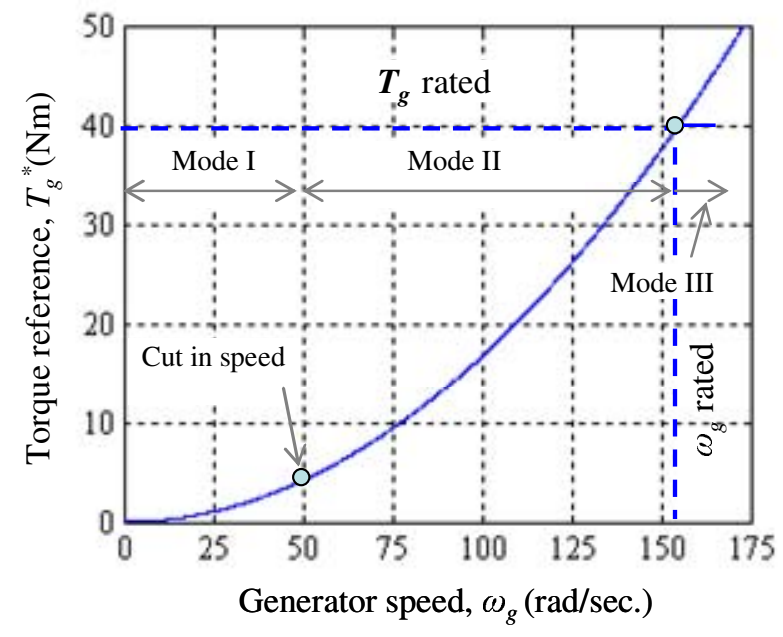

Figure 4. Generator torque reference versus speed.

be maintained. The control is linear and increase the duty cycle as a function of the over voltage amount. All the PI controllers are tuned using Ziegler-Nichols tuning method [13].

The vector control scheme used is based on a synchronously rotating reference frame as shown in figure 6 . 
The angular velocity of the rotating axis system $\omega$ is set in the controller and defines the electrical frequency at the load. The voltage balance across the inductor $L_{f}$ is given by 


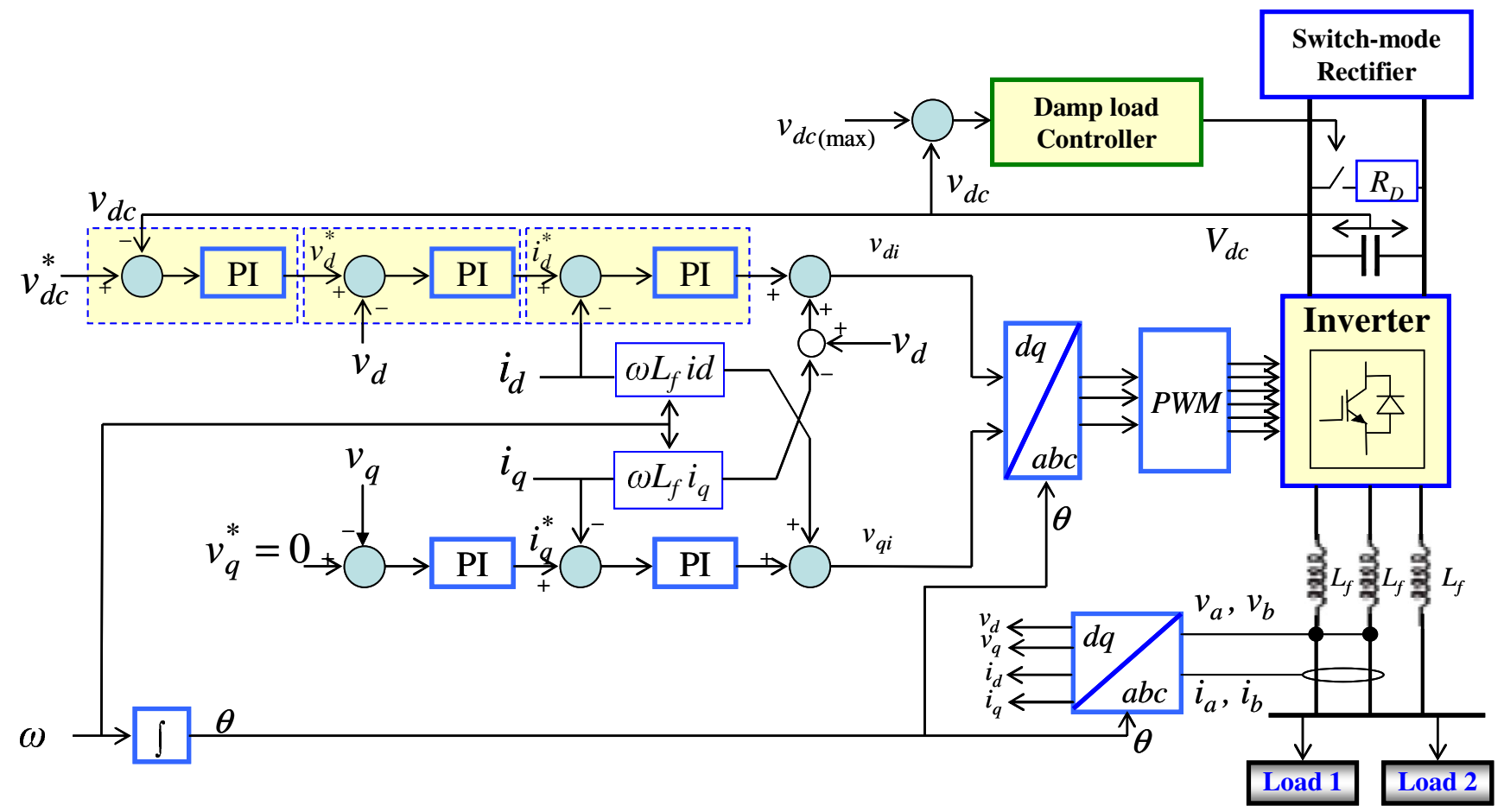

Figure 5. Vector control structure for stand alone mode of operation.

$$
\left[\begin{array}{l}
v_{a} \\
v_{b} \\
v_{c}
\end{array}\right]=R_{f}\left[\begin{array}{l}
i_{a} \\
i_{b} \\
i_{c}
\end{array}\right]+L_{f} \frac{d}{d t}\left[\begin{array}{l}
i_{a} \\
i_{b} \\
i_{c}
\end{array}\right]+\left[\begin{array}{l}
v_{a 1} \\
v_{b 1} \\
v_{c 1}
\end{array}\right]
$$

Where, $L_{f}$ and $R_{f}$ are the filter inductance and resistance respectively. $v_{a 1}, v_{a 2}, v_{a 3}$ represent voltages at the inverter output. $i_{a}, i_{b}$ and $i_{c}$ are the line currents.

The vector representation of a balanced three phase system and their equivalent vectors in a rotating dq reference frame is shown in figure 6 . Transforming the voltage equations using $d q$ transformation in the rotating reference frame:

$$
\begin{aligned}
& v_{d}=v_{d i}-R_{f} i_{d}-L_{f} \frac{d i_{d}}{d t}+\omega L_{f} i_{q} \\
& v_{q}=v_{q i}-R_{f} i_{q}-L_{f} \frac{d i_{q}}{d t}-\omega L_{f} i_{d}
\end{aligned}
$$

The instantaneous power in a three phase system is given by:

$$
P(t)=v_{a} i_{a}+v_{b} i_{b}+v_{c} i_{c}=\left[\begin{array}{lll}
v_{a} & v_{b} & v_{c}
\end{array}\right]\left[\begin{array}{lll}
i_{a} & i_{b} & i_{c}
\end{array}\right]^{\prime}
$$

Using $d q$ transformation, the active and reactive power is given by

$$
\begin{aligned}
& P=\frac{3}{2}\left(v_{d} i_{d}+v_{q} i_{q}\right) \\
& Q=\frac{3}{2}\left(v_{d} i_{q}+v_{q} i_{d}\right)
\end{aligned}
$$

If the reference frame is as $v_{q}=0$ and $v_{d}=|V|$, the equations for active and reactive power will be,

$$
\begin{aligned}
& P=\frac{3}{2}\left(v_{d} i_{d}\right)=\frac{3}{2}|V| i_{d} \\
& Q=\frac{3}{2}\left(v_{d} i_{q}\right)=\frac{3}{2}|V| i_{q}
\end{aligned}
$$

Therefore, active and reactive power can be controlled by controlling direct and quadrature current components, respectively.

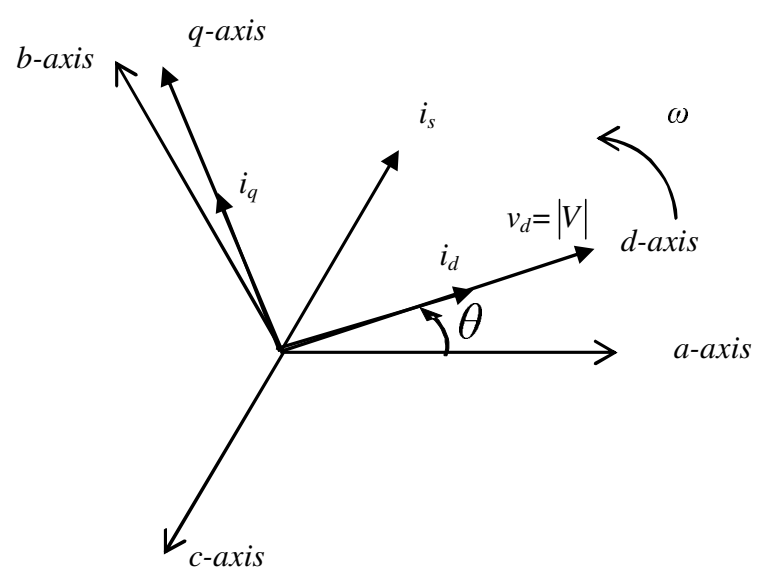

Figure 6. abc and rotating reference frame. 


\section{Results AND Discussions}

The model of the PMSG based variable speed wind turbine system of figure 1 is built using Matlab/Simpower dynamic system simulation software. The simulation model is developed based on a Kollmorgen $6 \mathrm{~kW}$ industrial permanent magnet synchronous machine. The parameters of the Turbine and PMSG used are given in Tble I. The power converter and the control algorithm are also implemented and included in the model. The sampling time used for the simulation is $20 \mu \mathrm{s}$.

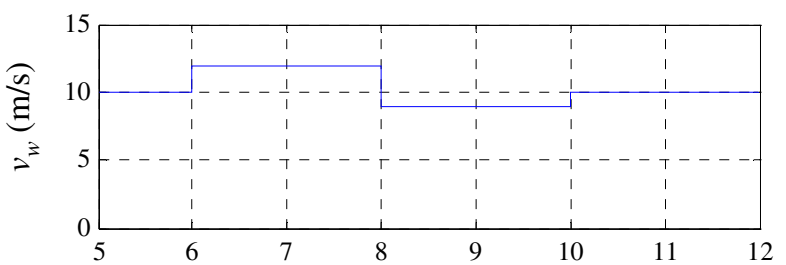

(a) Wind speed

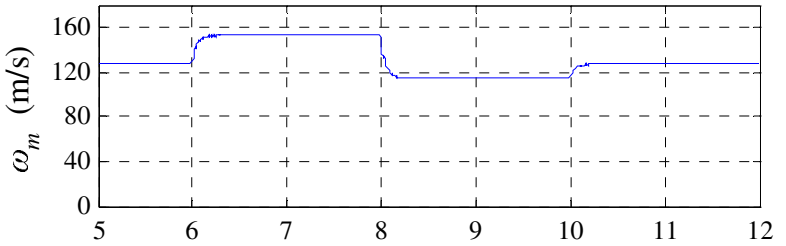

(b) Generator speed

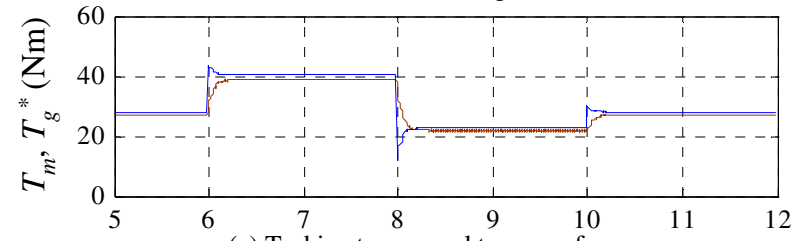

(c) Turbine torque and torque reference
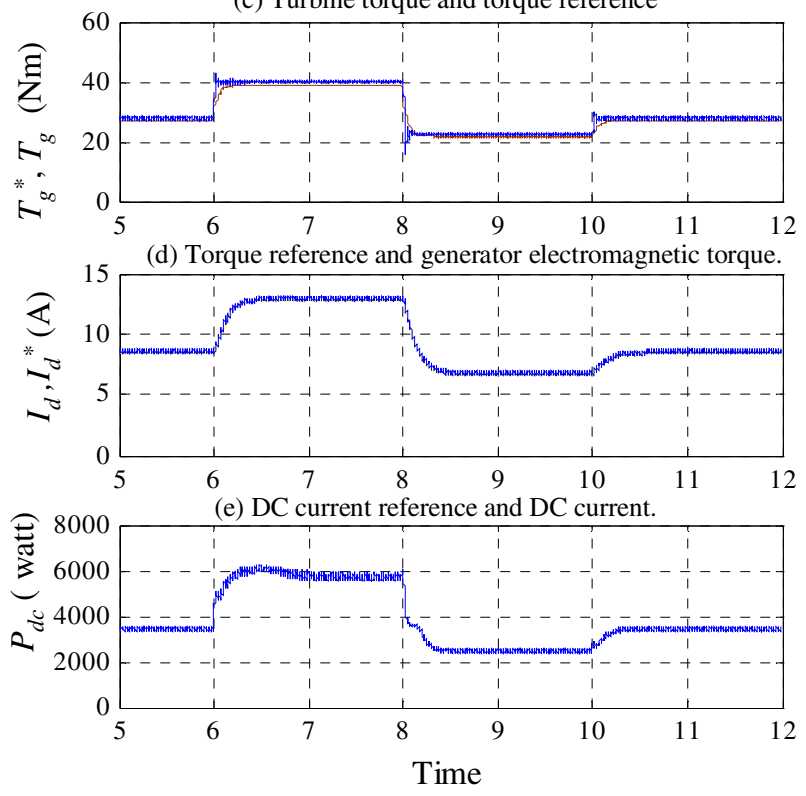

(f) DC power output

Figure 7. Response of the system for a step change of wind speed from $10 \mathrm{~m} / \mathrm{s}$ to $12 \mathrm{~m} / \mathrm{s}$ to $9 \mathrm{~m} / \mathrm{s}$ to $10 \mathrm{~m} / \mathrm{s}$.

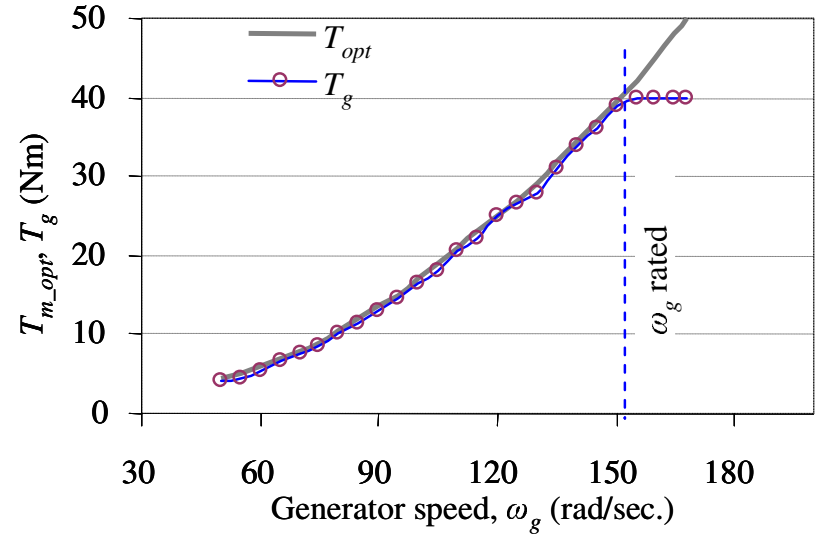

Figure 8. Optimum torque and generator torque.

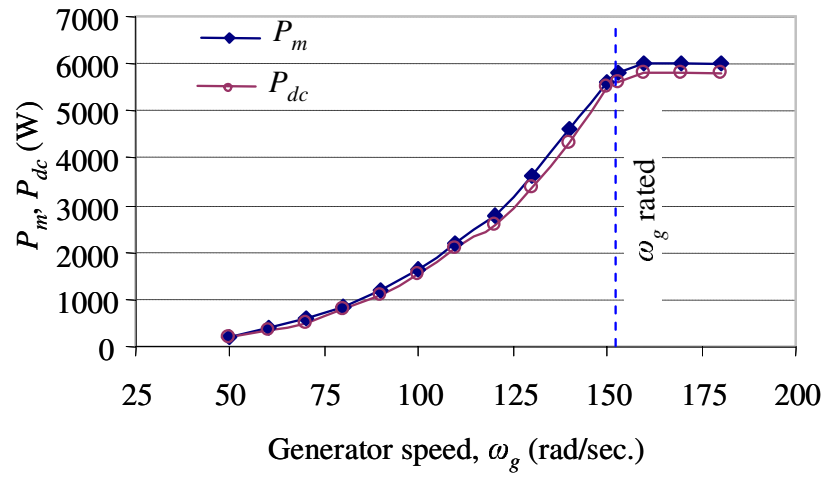

Figure 9. Turbine mechanical input power and Electrical output power.

Figure 7 shows the response of the system for a step change of wind speed from $10 \mathrm{~m} / \mathrm{s}$ to $12 \mathrm{~m} / \mathrm{s}$ to $9 \mathrm{~m} / \mathrm{s}$ and then comes back to $10 \mathrm{~m} / \mathrm{s}$. It is seen from figure 7 (c) that the generated torque reference follows the optimum mechanical torque of the turbine quite well. The generator electromagnetic torque also track the reference torque as shown in figure 7(d). Figure 7(e) shows the reference dc current and measured DC current. It is observed that the measured DC current follows the reference DC current and regulate the turbine torque to extract maximum power from the wind turbine. Figure 7(f) dc output power.

Figure 8 shows optimum torque versus speed as well as generator torque versus speed. Turbine mechanical input power and electrical output powers are shown in figure 9. It is observed that the torque and power follow the optimum curves up to the rated speed and extract maximum power.

The simulation results demonstrate that the controller works very well and shows very good dynamic and steady state performance. The control algorithm can be used to extract maximum power from the variable speed wind turbine under fluctuating wind.

Figure 10 shows the load voltage and current responses. Figure 10(a) and 10(b) show instantaneous and rms load voltages and figure $10(\mathrm{c})$ and $10(\mathrm{~d})$ show instantaneous and 
rms currents at a constant load. Figure 11 shows the frequency response, dc link voltage and modulation index of the PWM inverter at a constant load.

Figure 12 shows the load voltage, current and figure 13 shows the frequency response, dc link voltage and modulation index of the PWM inverter when the load is reduced to $50 \%$ during $3 s \leq t \leq 4 s$. Figure 12(a) and 12(b) show instantaneous
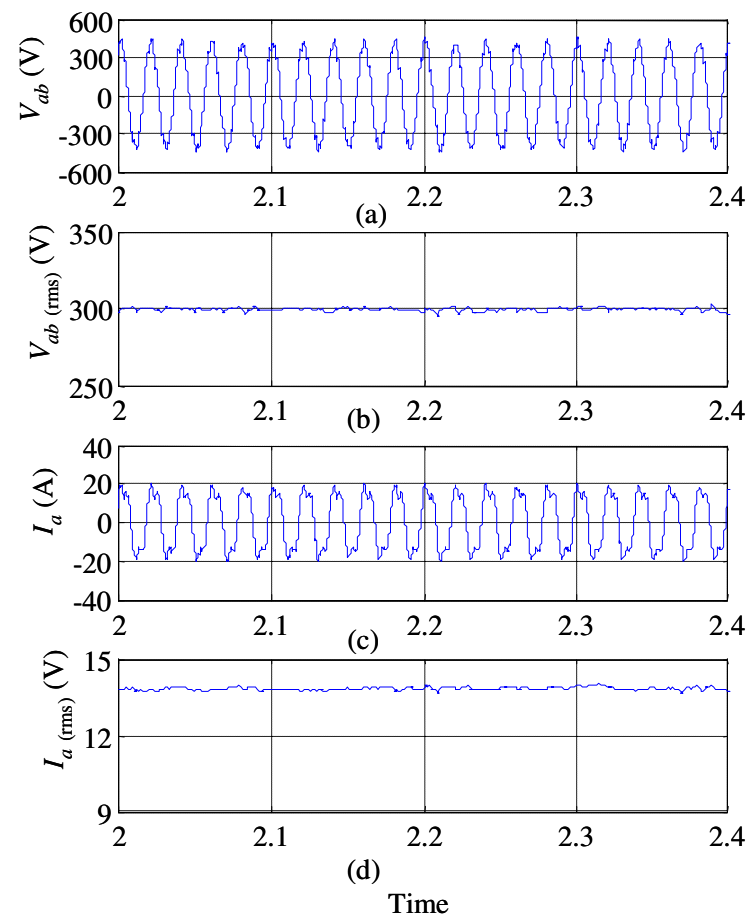

Figure 10. Voltage and current responses at a constant load.
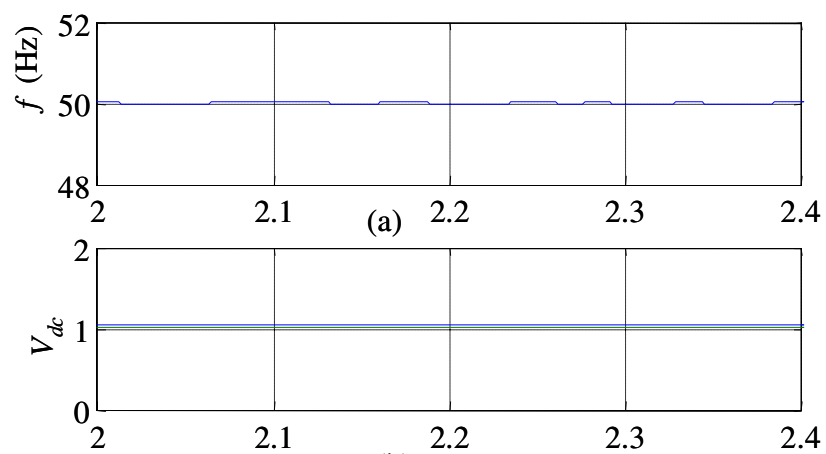

(b)

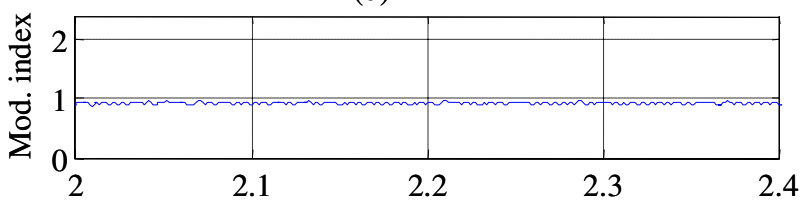

(c)

Time

Figure 11. Frequency response, DC link voltage and modulation index at a constant load. and rms voltages and figure 12(c) and 12(d) show the instantaneous and rms currents when the load is reduced to $50 \%$ at $t=3 \mathrm{~s}$ and remains at this value until $=4 \mathrm{~s}$ t. Figure 13 shows the corresponding frequency response, dc link voltage and modulation index. It is seen that the controller can regulate the load voltage and frequency quite well at constant load and under varying load condition.

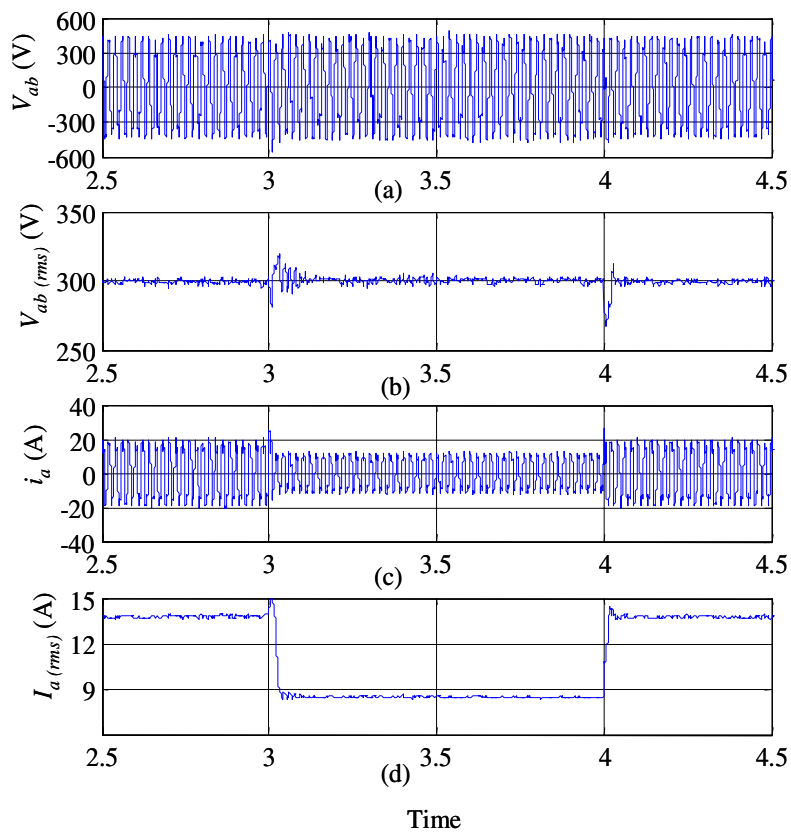

Figure 12. Voltage and current responses when load is reduced by $50 \%$.
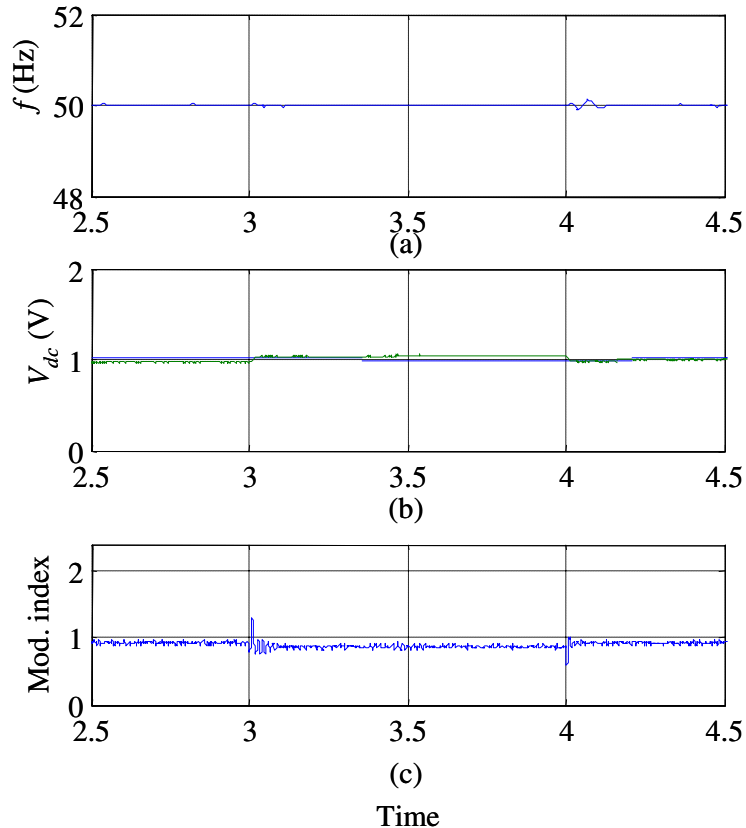

Figure 13. Frequency response, DC link voltage and modulation index when load is reduced by $50 \%$. 


\section{CONCLUSIONS}

Control strategy for a stand alone variable speed wind turbine with a PMSG is presented in this paper. A simple control strategy for the generator side converter to extract maximum power is discussed and implemented using Simpower dynamic system simulation software. The controller is capable to maximize output of the variable speed wind turbine under fluctuating wind. The load side PWM inverter is controlled using vector control scheme to maintain the amplitude and frequency of the inverter out put voltage. It is seen that the controller can maintain the load voltage and frequency quite well at constant load and under varying load condition. The generating system with the proposed control strategy is suitable for a small scale standalone variable speed wind turbine installation for remote area power supply. The simulation results demonstrate that the controller works very well and shows very good dynamic and steady state performance

\section{ACKNOWLEDGMENT}

The authors greatly acknowledge the support and cooperation of hydro Tasmania personnel in providing data and advice on the operation of remote area power supply system.

Table I: Parameter of the Turbine-Generator system

\begin{tabular}{|l|l|}
\hline Wind turbine & $1.225 \mathrm{Kg} / \mathrm{m}^{3}$ \\
\hline Density of air & $1.06 \mathrm{~m}^{2}$ \\
\hline Area swept by blades, $A$ & $1.67 \times 10^{-3} \mathrm{Nm} /(\mathrm{rad} / \mathrm{s})^{2}$ \\
\hline Optimum coefficient, $K_{\text {opt }}$ & $12 \mathrm{~m} / \mathrm{s}$ \\
\hline Base wind speed & 10 \\
\hline PMSG & $153 \mathrm{rad} / \mathrm{sec}$ \\
\hline No. of poles & $12 \mathrm{~A}$ \\
\hline Rated speed & $0.425 \Omega$ \\
\hline Rated current & $0.433 \mathrm{~Wb}$ \\
\hline Armature resistance, $\mathrm{R}_{\mathrm{s}}$ & $8.4 \mathrm{mH}$ \\
\hline Magnet flux linkage & $40 \mathrm{Nm}$ \\
\hline Stator inductance, $L_{s}$ & $6 \mathrm{KW}$ \\
\hline Rated torque & \\
\hline Rated power & \\
\hline
\end{tabular}

\section{REFERENCES}

[1] Müller, S., Deicke, M., and De Doncker, Rik W.: 'Doubly fed induction genertaor system for wind turbines', IEEE Industry Applications Magazine, May/June, 2002, pp. 26-33.
[2] H. Polinder, F. F. A. van der Pijl, G. J. de Vilder, P. J Tavner, "Comparison of direct-drive and geared generator concepts for wind turbines," IEEE Trans. on energy conversion, vol . 21, no. 3, pp. 725-733, Sept. 2006.

[3] T. F. Chan, L. L. Lai, "Permanenet-magnet machines for distributed generation: a review," in proc. 2007 IEEE power engineering annual meeting, pp. 1-6.

[4] M. De Broe, S. Drouilhet, and V. Gevorgian, "A peak power tracker for small wind turbines in battery charging applications," IEEE Trans. Energy Convers., vol. 14, no. 4, pp. 1630-1635, Dec. 1999.

[5] R. Datta and V. T. Ranganathan, "A method of tracking the peak power points for a variable speed wind energy conversion system," IEEE Trans. Energy Convers., vol. 18, no 1, pp. 163-168, Mar. 1999.

[6] K. Tan and S. Islam, "Optimal control strategies in energy conversion of PMSG wind turbine system without mechanical sensors," IEEE Trans. Energy Convers., vol. 19, no. 2, pp. 392-399, Jun. 2004.

[7] S. Morimoto, H. Nakayama, M. Sanada, and Y. Takeda, "Sensorless Output Maximization Control for VariableSpeed Wind Generation System Using IPMSG", IEEE Trans. Ind. Appl., vol. 41, no. 1, pp. 60-67, Jan. 2005.

[8] M. Chinchilla, S. Arnaltes, and J. C. Burgos, "Control of Permanent-Magnet Generators Applied to VariableSpeed Wind-Energy Systems Connected to the Grid" IEEE Trans. on Energy Conver., vol 21, no. 1, March 2006.

[9] D.J. Perreault and V. Caliskan, "Automotive Power Generation and Control", IEEE Transactions on Power Electronics, Vol. 19, no. 3, pp. 618-630, May 2004.

[10] W.L. Soong and N. Ertugrul, "Inverterless high-power interior permanent-magnet automotive alternator", IEEE Transactions on Industry Applications. Vol.40, no.4, pp.1083-1091, July 2004.

[11] D. M. Whaley, W. L. Soong, N. Ertugrul, "Investigation of switched-mode rectifier for control of small-scale wind turbines", in proc. IEEE Industry applications society annual meeting, pp. 2849-2856, 2005.

[12] E. Muljadi, S. Drouilhet, R. Holz, V. Gevorgian, "Analysis of permanent magnet genertaor for wind power battery charging", in proc. IEEE 1996 Industry applications society annual meeting, pp. 541-548.

[14] K. J. Astrom and T. Hagglund, PID controllers: Theory, Design and Tuning. Research Triangle Park, NC: Instrument Society of America, 1995. 
